\title{
Computational Analysis of Third-Grade Liquid Flow with Cross Diffusion Effects: Application to Entropy Modeling
}

\author{
K. Loganathan ${ }^{1(\otimes)} \mathbb{D}$, A. Charles Sagayaraj ${ }^{2}$, Amelec Viloria $^{3,4}$, Noel Varela ${ }^{3}$, \\ Omar Bonerge Pineda Lezama ${ }^{5}$, and Luis Ortiz-Ospino ${ }^{6}$ \\ 1 Department of Mathematics, Faculty of Engineering, \\ Karpagam Academy of Higher Education, Coimbatore 641021, Tamilnadu, India \\ loganathankaruppusamy304@gmail.com \\ 2 Department of Mathematics, Sri Vidya Mandir Arts and Science College, \\ Katteri, Uthangarai, Tamilnadu, India \\ 3 Universidad de la Costa, Barranquilla, Colombia \\ 4 Universidad Peruana de Ciencias Aplicadas, Lima, Peru \\ 5 Universidad Tecnológica Centroamericana (UNITEC), San Pedro Sula, Honduras \\ ${ }^{6}$ Universidad Simon Bolivar, Barranquilla, Colombia
}

\begin{abstract}
The key goal of this current study is to analyze the entropy generation with cross diffusion effects. The third-grade type nonNewtonian fluid model is used in this study. The current flow problem is modelled with stretching plate. Modified Fourier heat flux is replaced the classical heat flux. The appropriate transformation is availed to convert the basic boundary layers equations into ODEs and then verified by homotopy algorithm. The consequences of various physical quantities on temperature, velocity, entropy and concentration profile are illustrated graphically.
\end{abstract}

Keywords: Third grade fluid $\cdot$ Linear stretching sheet $\cdot$ Homotopy Analysis Method (HAM) - Soret and Dufour effects · Entropy generation

\section{Introduction}

Third grade fluid is one of the notable sub kinds of non-Newtonian fluids. The non-Newtonian fluid flow due to the stretching surface is the important area of research due to its broad applications in many industrial and production domains such as, rolling of polymer films, extrusion of metallic sheets, etc. The study on 2nd grade fluid which passed through the stretching sheet is numerically discussed including the variations in thermophysical properties like thermal conductivity, viscosity [1]. It is shown that Eckert number increases the heat transport rate. Hydromagnetic mixed convective heat transfer of 3rd-grade fluid with gyrotactic microorganism is examined [2]. Unsteady flow of power law fluid with uniform velocity is evaluated [3]. With the consideration of heat source and

(C) Springer Nature Switzerland AG 2020

Y. Tan et al. (Eds.): ICSI 2020, LNCS 12145, pp. 525-534, 2020.

https://doi.org/10.1007/978-3-030-53956-6_48 
heat sink of MHD flow over a oscillatory stretching sheet is numerically studied [4]. With the impact of chemical reaction, the fourth grade fluid through porous plate of MHD radiative fluid is investigated [5]. In addition to MHD nanofluid, the electrically conductive fluid that of second grade with suction parameter is developed [6]. For the application of bio magnetic the third grade fluid is correlated numerically [7]. The modified Fourier heat flux model for the study of carreau fluid is explored numerically [8]. The various features and applications of non-Newtonian fluids are studied in ref's [9-15].

There are several techniques available to solve nonlinear problems. The homotopy analysis method (HAM) is initially constructed by Liao [16] in 1992. Moreover, he altered with a non-zero auxiliary parameter [17] . This parameter shows the way to calculate the convergence rate. It also offers great independence to choose the base functions of the solutions. A few more studies about this technique was seen in previous works $[18,19]$.

Inspired by the above literature surveys, we are constructing a steady 3rdgrade liquid flow with considering radiation, and convective heating effects. Dufour and Soret effects are examined. The system of entropy is discussed briefly for various parameters.

\section{Mathematical Formation}

The steady third grade incompressible two dimensional chemically reactive fluid flow due to stretchy surface is considered. The sheet to be stretchy by the pair of same and inverse forces with velocity $\left(u_{w}=a x\right), a>0$, a is known as stretchy rate. The free stream velocity is $u_{\infty} .\left(C_{\infty}\right)$ and $\left(T_{\infty}\right)$ are the free stream concentration and temperature and in order. The governing equations with boundary conditions are listed below

$$
\begin{gathered}
\frac{\partial u}{\partial x}+\frac{\partial v}{\partial y}=0 \\
u \frac{\partial u}{\partial x}+v \frac{\partial u}{\partial y}=\mu \frac{\partial^{2} x}{\partial y^{2}}+\frac{\alpha_{1}^{*}}{\rho}\left(u \frac{\partial^{3} u}{\partial y^{2} \partial x}+v \frac{\partial^{3} u}{\partial y^{3}}+\frac{\partial u}{\partial x} \frac{\partial^{2} u}{\partial y^{2}}+3 \frac{\partial u}{\partial y} \frac{\partial^{2} u}{\partial y^{2}}\right) \\
+2 \frac{\partial_{2}^{*}}{\rho} \frac{\partial u}{\partial y} \frac{\partial^{2} u}{\partial x \partial y}+6 \frac{\beta^{*}}{\rho}\left(\frac{\partial u}{\partial y}\right)^{2} \frac{\partial^{2} u}{\partial y^{2}}+g\left[\beta_{T}\left(T-T_{\infty}\right)\right. \\
\left.+\beta_{C}\left(C-C_{\infty}\right)\right] \\
\frac{\partial T}{\partial x} u+\frac{\partial T}{\partial y} v=\frac{Q}{\rho c_{p}}\left(T-T_{\infty}\right)+\frac{k}{\rho c_{p}} \frac{\partial^{2} T}{\partial y^{2}}-\frac{1}{\rho c_{p}} \frac{\partial q_{r}}{\partial y}+\frac{D_{m} k_{m}}{c_{s} c_{p}} \frac{\partial^{2} C}{\partial y^{2}} \\
\frac{\partial u}{\partial x} u+\frac{\partial C}{\partial y} v=D_{m} \frac{\partial^{2} C}{\partial y^{2}}+\frac{D_{m} k_{m}}{T_{m}} \frac{\partial^{2} T}{\partial y^{2}}-k_{m}\left(C-C_{\infty}\right)
\end{gathered}
$$


The boundary points stated as $u=\left(u_{w}(x)=a x\right),(v=0),\left(-k \frac{\partial T}{\partial y}=h_{f}\left(T_{f}-\right.\right.$ $\left.\left.T_{w}\right)\right),\left(C=C_{w}\right)$ at $(y=0)$,

$$
u(\rightarrow 0), T\left(\rightarrow T_{\infty}\right),\left(C \rightarrow C_{\infty}\right) \text { as } y(\rightarrow \infty)
$$

where $u \& v$ (=velocity components along the $x \& y$-direction), $\mu$ (=kinematic viscosity), ( $\left.\alpha_{1}^{*}, \alpha_{2}^{*} \& \beta_{1}^{*}\right)$ (=material parameters), $\rho$ (=fluid density), $\left(\beta_{T}, \beta_{C}\right)$ (=coefficient of thermal and concentration expansions), $c_{p}$ (=specific heat), $c_{s}$ (=concentration susceptibility), $Q$ (=heat capacity of ordinary fluid), $q_{r}$ (= radiative heat flux), $C$ (=concentration), $C_{w}$ (= fluid wall concentration), $D_{m}$ (=mass diffusion coefficient), $k_{m}$ (=first order chemical reaction parameter).

Incorporating the Cattaneo-Christov heat flux into energy equation, we get

$$
\begin{array}{r}
u \frac{\partial T}{\partial x}+v \frac{\partial T}{\partial y}+2 u v \frac{\partial^{2} T}{\partial x \partial y}+\lambda\left(u^{2} \frac{\partial^{2} T}{\partial x^{2}}+v^{2} \frac{\partial^{2} T}{\partial y^{2}}+\left(u \frac{\partial u}{\partial x}+v \frac{\partial u}{\partial y}\right) \frac{\partial T}{\partial x}\right. \\
\left.+\left(u \frac{\partial v}{\partial x}+v \frac{\partial v}{\partial y}\right) \frac{\partial T}{\partial y}\right)=\frac{k}{\rho c_{p}} \frac{\partial^{2} T}{\partial y^{2}}-\frac{1}{\rho c_{p}} \frac{\partial q_{r}}{\partial y}+\frac{D_{m} k_{T}}{c_{s} c_{p}} \frac{\partial^{2} C}{\partial y^{2}}+\frac{Q}{\rho c_{p}}\left(T-T_{\infty}\right) .
\end{array}
$$

Consider the transformations given below

$$
\eta=\sqrt{\frac{a}{\mu}} y, v=-\sqrt{a \mu} F(\eta), u=a x F^{\prime}(\eta), \phi(\eta)=\frac{C-C_{\infty}}{C_{w}-C_{\infty}}, \theta(\eta)=\frac{T-T_{\infty}}{T_{f}-T_{\infty}}
$$

Using the above mentioned transformations we retrive the ODE system as follows

$$
\begin{aligned}
-F^{\prime 2}+F F^{\prime \prime}+\left(3 \alpha_{1}+2 \alpha_{2}\right){F^{\prime \prime}}^{2}+6 \beta R e F^{\prime \prime \prime} F^{\prime \prime 2}+F^{\prime \prime \prime} & +\alpha_{1}\left(2 F^{\prime} F^{\prime \prime \prime}-F F^{i v}\right) \\
& +\lambda_{1}(\theta+N \phi)=0
\end{aligned}
$$

$$
\begin{gathered}
\left(1+\frac{4}{3} R d\right) \theta^{\prime \prime}+\operatorname{Pr} f \theta^{\prime}+Q_{H} \theta-\gamma\left(F F^{\prime} \theta^{\prime}+F^{2} \theta^{\prime \prime}\right)+\operatorname{Pr} D_{F} \phi^{\prime \prime}=0 \\
\frac{1}{S c} \phi^{\prime \prime}+F \phi^{\prime}-C_{r} \phi+S r \theta^{\prime \prime}=0
\end{gathered}
$$

Boundary conditions are

$$
\begin{array}{r}
F^{\prime}(\eta)=1, F(\eta)=0, \theta^{\prime}(\eta)=-B i(1-\theta(\eta)), \phi(\eta)=1 \text { at } \eta=0 \\
F^{\prime}(\eta) \rightarrow 0, \theta(\eta) \rightarrow 0, \phi(\eta) \rightarrow 0 \text { as } \eta \rightarrow \infty
\end{array}
$$

where $\alpha_{1}=\alpha_{1}^{*} a / \rho \mu, \alpha_{2}=\alpha_{2}^{*} a / \rho \mu$ and $\beta=\beta^{*} a^{2} / \rho \mu$ (=fluid parameters), $R e=$ $a x^{2} / \mu$ (=Reynolds number), $\operatorname{Pr}=\rho \mu c_{p} / k$ (= Prandtl number), $Q_{H}=Q / a \rho c_{p}$ (=Heat generation), $\gamma=\lambda a$ (=thermal relaxation), $S c=\mu / D_{B}$ (=Schmidt number), $C_{r}=k_{m} / a\left(=\right.$ Chemical reaction), $\lambda 1=G r / R e^{2}$ (=local buoyancy parameter), $G r=g \beta_{T}\left(T_{w}-T_{\infty}\right) x^{3} / \mu^{2}$ (=Grashof number), $N=\beta_{C}\left(C_{w}-C_{\infty}\right) / \beta_{T}\left(T_{w}-\right.$ 
$T_{\infty}$ )(=buoyancy ratio parameter), $R d=4 \sigma_{1} T_{\infty}^{3} / k k_{*}$ (=Radiation parameter), $D_{F}=D_{m} k_{T} / \mu c_{s} c_{p} \frac{C_{w}-C_{\infty}}{T_{w}-T_{\infty}}$ (= Dufour number), $S r=\frac{D_{m} k_{T}}{\mu T_{m}} \frac{\left(T_{w}-T_{\infty}\right)}{\left(C_{w}-C_{\infty}\right)}(=$ Soret number).

Heat and mass transfer rate in dimensionless forms are

$$
R e^{\frac{-1}{2}} N u_{x}=-\left(1+\frac{4}{3} R d\right) \theta^{\prime}(0), R e^{\frac{-1}{2}} S h_{x}=-\phi^{\prime}(0) .
$$

\section{Analytical Procedure and Convergence Study}

HAM has been used last twenty years to solve the non-linear system of ODE occurring in various fields. The nonlinear ODE are solved with the aid of HAM algorithm. This algorithm is computed through MATHEMATICA software in our personal computer with $8 \mathrm{~GB}$ RAM and $2.30 \mathrm{GHz}$ Processor.

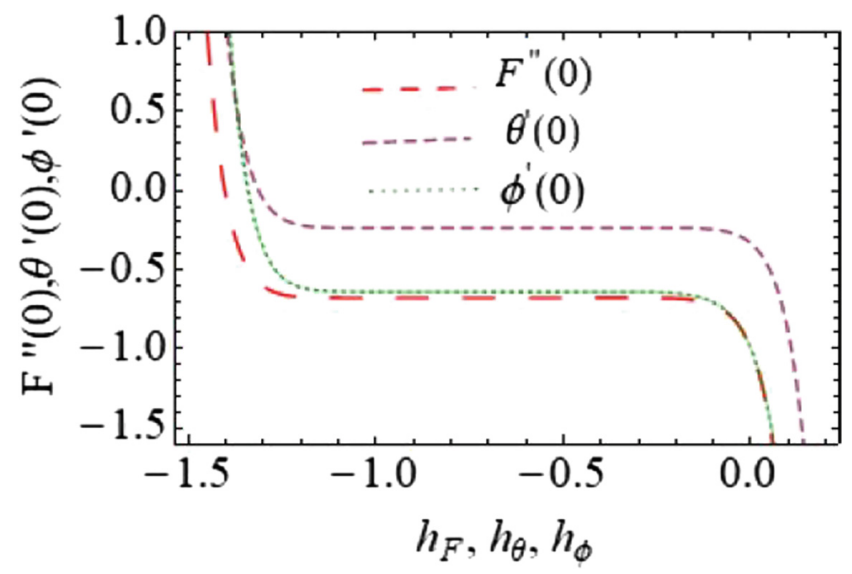

Fig. 1. h-curves for $h_{F, \theta, \phi}$.

Based on the Fig. 1, the auxiliary parameters have the range $-1.2 \leq h_{F} \leq$ $0.3,-1.3 \leq h_{\theta} \leq 0.1,-1.3 \leq h_{\phi} \leq 0.3$. Approximatley we fixed the $h$ values as $h_{F}=h_{\theta}=h_{\phi}=-0.7$ (Table 1$)$.

\section{Entropy Optimization}

The entropy minimization optimization for fluid friction, heat and mass transfer irreversibility's are given below:

$$
S_{g e n}^{\prime \prime \prime}=\frac{K_{1}}{T_{\infty}^{2}}\left[\left(\frac{\partial T}{\partial y}\right)^{2}+\frac{16 \sigma^{*} T_{\infty}^{3}}{3 k k^{*}}\left(\frac{\partial T}{\partial y}\right)^{2}+\frac{\mu}{T_{\infty}}+\left[\left(\frac{\partial u}{\partial y}\right)^{2}+\frac{R D}{C_{\infty}}\left(\frac{\partial c}{\partial y}\right)^{2}+\frac{R D}{T_{\infty}}\left(\frac{\partial T}{\partial y}\right)\left(\frac{\partial c}{\partial y}\right)\right.\right.
$$


Table 1. Displays the convergence solutions of HAM in order of approximation when $\operatorname{Pr}=0.9, \alpha_{1}=0.1, S c=0.9, D_{F}=0.5, R e=0.1, \beta=0.1, \alpha_{2}=0.1, \gamma=0.1, B i=$ $0.5, R d=0.3, \lambda_{1}=0.2, N=0.1, S r=0.3, Q_{H}=-0.3, h=-0.7, C_{r}=0.1$.

\begin{tabular}{l|l|l|l}
\hline Order & $-F^{\prime \prime}(0)$ & $\theta^{\prime}(0)$ & $-\phi^{\prime}(0)$ \\
\hline 1 & 0.72116 & 0.23913 & 0.72777 \\
\hline 5 & 0.67605 & 0.23555 & 0.63669 \\
\hline 10 & 0.67817 & 0.23648 & 0.63945 \\
\hline 15 & 0.67803 & 0.23643 & 0.63897 \\
\hline 20 & 0.67801 & 0.23644 & 0.63901 \\
\hline 25 & 0.67803 & 0.23644 & 0.63903 \\
\hline 30 & 0.67803 & 0.23644 & 0.63903 \\
\hline 40 & 0.67803 & 0.23644 & 0.63903 \\
\hline 50 & 0.67803 & 0.23644 & 0.63903 \\
\hline
\end{tabular}

Dimensionless system of entropy generation is defined as:

$$
E_{G}=\operatorname{Re}\left(1+\frac{4}{3} R d\right) \theta^{\prime 2}+\operatorname{Re}\left(\frac{B r}{\Omega}\right) f^{\prime \prime 2}+\operatorname{Re}\left(\frac{\zeta}{\Omega}\right)^{2} \lambda \phi^{\prime 2}+R e \frac{\zeta}{\Omega} \lambda \phi^{\prime} \theta^{\prime}
$$

\section{Validation}

In order to validate our numerical procedure, the results are validated with earlier report of Maria et al. [10]. The comparison results are given in Table 2.

Table 2. Comparison in absence of $D_{F}=0, S R=0, \omega=0, R d=0, C_{r}=0, \lambda_{1}=$ $0, N=0, Q_{H}=0$.

\begin{tabular}{l|l|l|l|l|l|l}
\hline \multirow{2}{*}{ Order } & $-f^{\prime \prime}(0)$ & \multicolumn{2}{l|}{$-\theta^{\prime}(0)$} & \multicolumn{2}{l}{$-\phi^{\prime}(0)$} & \\
\cline { 2 - 7 } & Ref. [10] & Current & Ref. [10] & Current & Ref. [10] & Current \\
\hline 1 & 0.81450 & 0.81450 & 0.72778 & 0.72778 & 0.72778 & 0.72778 \\
\hline 5 & 0.81221 & 0.81221 & 0.58070 & 0.58070 & 0.64933 & 0.64933 \\
\hline 8 & 0.81235 & 0.81235 & 0.57779 & 0.57779 & 0.64835 & 0.64835 \\
\hline 14 & 0.81235 & 0.81235 & 0.57871 & 0.57871 & 0.64873 & 0.64873 \\
\hline 17 & 0.81235 & 0.81235 & 0.57878 & 0.57878 & 0.64873 & 0.64873 \\
\hline 25 & 0.81235 & 0.81235 & 0.57878 & 0.57878 & 0.64873 & 0.64873 \\
\hline 30 & 0.81235 & 0.81235 & 0.57878 & 0.57878 & 0.64873 & 0.64873 \\
\hline 35 & 0.81235 & 0.81235 & 0.57878 & 0.57878 & 0.64873 & 0.64873 \\
\hline
\end{tabular}



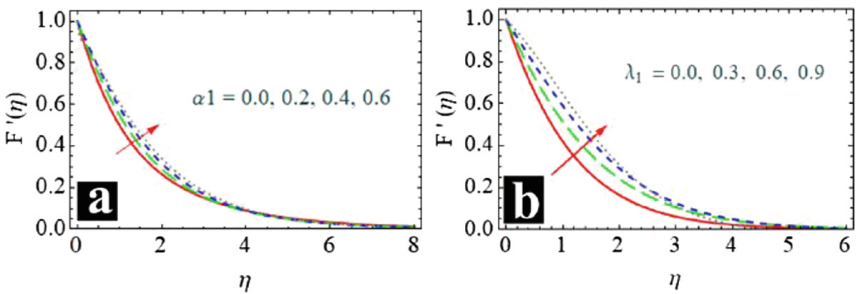

Fig. 2. Variation in $\left(F^{\prime}(\eta)\right)$ for $\alpha_{1} \& \lambda_{1}$.
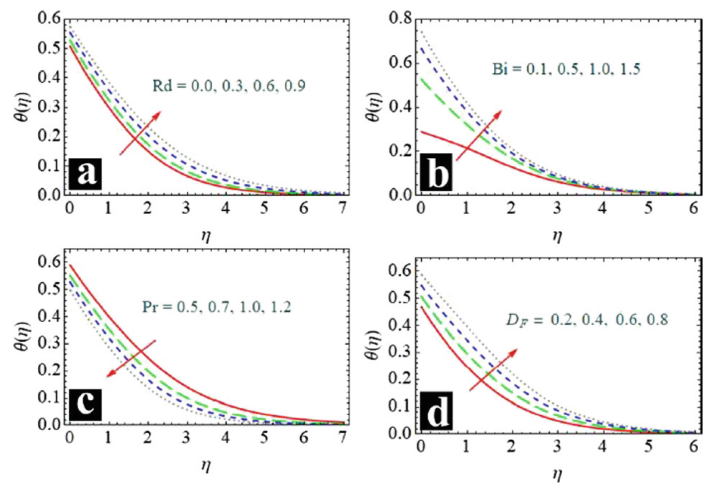

Fig. 3. Variation in $(\theta(\eta))$ for $R d, B i, P r$ and $D_{F}$.
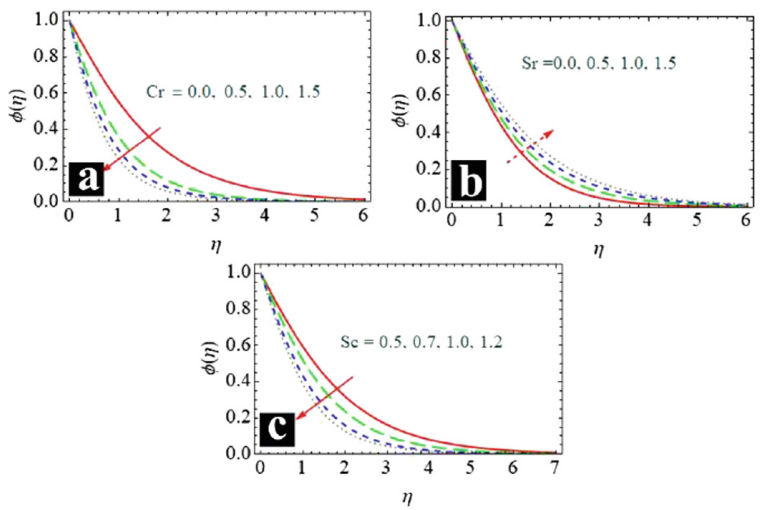

Fig. 4. Variation in $(\phi(\eta))$ for $C r, S r$ and $S c$. 


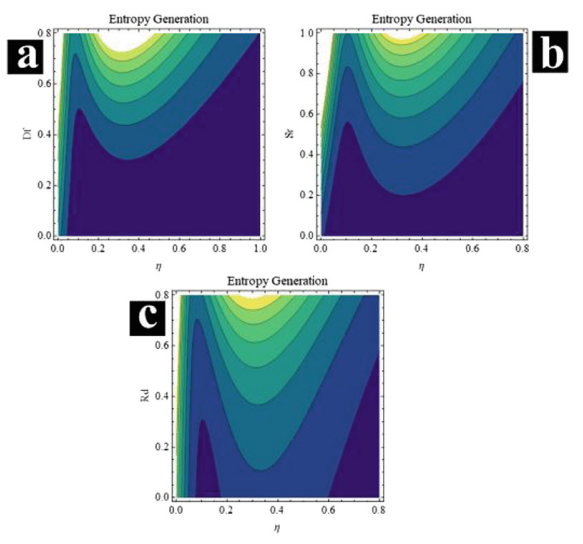

Fig. 5. Variation in $\left(E_{G}\right)$ for $D_{F}, S r$ and $R d$.

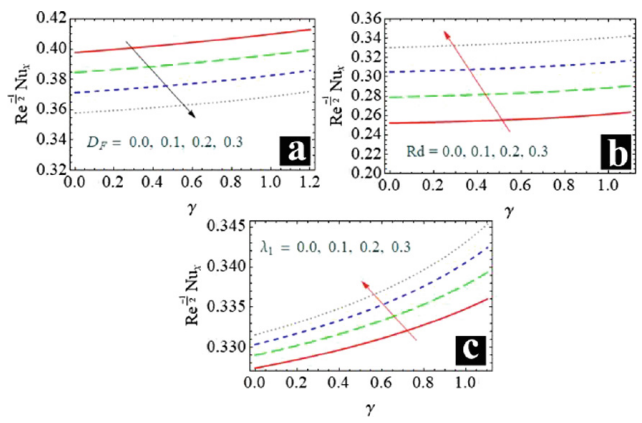

Fig. 6. Effect of $N u_{x}$ for values of $D_{F}, R d$ and $\lambda_{1}$.

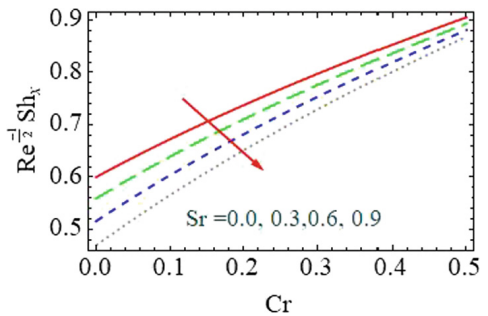

Fig. 7. Effect of $S h_{x}$ for values of $C r$ and $S r$. 


\section{Results and Discussion}

In this section, we examine the impacts of physical quantities on temperature $(\theta(\eta))$, velocity $\left(F^{\prime}(\eta)\right)$, entropy $\left(E_{G}\right)$ and concentration profiles $(\Phi(\eta))$ with the fixed values $\operatorname{Pr}=0.9, S c=0.9, R e=0.14, \alpha_{1}=0.1, \alpha_{2}=0.1, \beta=0.1$, $\gamma=0.1, D_{F}=0.5, S r=0.3, B i=0.5, R d=0.3, \lambda_{1}=0.2, N=0.1, Q_{H}=-0.3$, $h=-0.7$ and $C r=0.1$.

Figure 1 describes the effect of velocity profile $\left(F^{\prime}(\eta)\right)$ on material fluid parameter $\left(\alpha_{1}\right)$ and mixed convection parameter $\left(\lambda_{1}\right)$. From Fig. 1(a \& b), we have seen an increase in $\alpha_{1}$ and $\lambda_{1}$ the velocity profile $\left(F^{\prime}(\eta)\right)$ rises. Figure 2 revels the temperature profile $(\theta(\eta))$ for different parameters. In Fig. 2(a, b, d), we note that, the $(\theta(\eta))$ enhances for the augmentation in $R d, B i$ and $D_{F}$ and it diminishes for the higher values of Prandtl number $\operatorname{Pr}$ as shown in Fig. 2c. Figure 3 depicts the different effects of $C r, S r$, and $S c$ on concentration profile. From Fig. 3(a) and Fig. 3(c) concentration profile $(\Phi(\eta))$ is inversely proportional to the higher $\mathrm{Cr}$ and $S c$. Whereas in Fig. 3(b), it is found that $(\Phi(\eta))$ increases with augments in $S r$. Figures $4(\mathrm{a}-\mathrm{c})$ shows the effects of $D_{F}, S r$ and $R d$ on $E_{G}$ (entropy generation profile). From these plots we obtain that the system of entropy enhances for the larger values of $D_{F}, S r$ and $R d$.

From Fig. 5(a) we note that the Nusselt number $\left(N u_{x}\right)$ decreases with increases in $D_{F}$. Also, in Fig. 5(b) and Fig. 5(c), it is noted that $N u_{x}$ decrease with upsurge in $R d$ and $\gamma$. By increasing the $D_{F}$, fluid resits to move the hotter side of the sheet that subsequently $N u_{x}$ decreases. In addition, it is noted that as we increase the $R d$ and $\gamma$ the $N u_{x}$ enhances. Figure 6 exposes the mass transfer rate for the combined parameters $S r$ and $C r$. We noted that decreasing trend in mass transfer for larger $\mathrm{Sr}$ and mass transfer rate enhance for $\mathrm{Cr}$.

\section{Conclusion}

The salient outcomes of $3^{r d}$-grade fluid flow with Soret and Dufour effects along with entropy calculation is stated as follows:

1 Higher range of mixed convection parameter $\left(\lambda_{1}\right)$ and fluid parameter $\left(\alpha_{1}\right)$ intensifying the velocity profile.

2 Entropy of the system enhances with radiation, Sored and Dufour numbers.

3 Mass transfer rate rises with chemical reaction and reduces with Soret number.

\section{References}

1. Akinbobola, T.E., Okoya, S.S.: The flow of second grade fluid over a stretching sheet with variable thermal conductivity and viscosity in the presence of heat source/sink. J. Niger. Math. Soc. 34(3), 331-342 (2015). https://doi.org/10.1016/ j.jnnms.2015.10.002 
2. Alzahrani, E.O., Shah, Z., Dawar, A., Malebary, S.J.: Hydromagnetic mixed convective third grade nanomaterial containing gyrotactic microorganisms toward a horizontal stretched surface. Alexandria Eng. J. 58(4), 1421-1429 (2019). https:// doi.org/10.1016/j.aej.2019.11.013

3. Ahmed, J., Mahmood, T., Iqbal, Z., Shahzad, A., Ali, R.: NU SC. J. Mol. Liq. (2016). https://doi.org/10.1016/j.molliq.2016.06.022

4. Ali, N., Ullah, S., Sajid, M., Abbas, Z.: MHD flow and heat transfer of couple stress fluid over an oscillatory stretching sheet with heat source/sink in porous medium. Alexandria Eng. J. (2016). https://doi.org/10.1016/j.aej.2016.02.018

5. Arifuzzaman, S.M., Khan, S., Al-mamun, A., Rezae-rabbi, S., Biswas, P., Karim, I.: Hydrodynamic stability and heat and mass transfer flow analysis of MHD radiative fourth-grade fluid through porous plate with chemical reaction. J. King Saud Univ. Sci. (2018). https://doi.org/10.1016/j.jksus.2018.12.009

6. Cortell, R.: Flow and heat transfer of an electrically conducting fluid of second grade over a stretching sheet subject to suction and to a transverse magnetic field. Int. J. Heat Mass Transf. 49, 1851-1856 (2006). https://doi.org/10.1016/j. ijheatmasstransfer.2005.11.013

7. Ghosh, S.K.: Unsteady non-Newtonian fluid flow and heat transfer: a bio-magnetic application Sushil Kumar Ghosh. J. Magn. Magn. Mater. (2017). https://doi.org/ 10.1016/j.jmmm.2017.07.050

8. Nazir, U., Saleem, S., Nawaz, M., Sadiq, M.A., Alderremy, A.A.: Study of transport phenomenon in Carreau fluid using Cattaneo-Christov heat flux model with temperature dependent diffusion coefficients. Phys. A Stat. Mech. its Appl. 123921 (2020). https://doi.org/10.1016/j.physa.2019.123921

9. Waqas, M., Hayat, T., Farooq, M., Shehzad, S.A., Alsaedi, A.: Cattaneo-Christov heat flux model for flow of variable thermal conductivity generalized Burgers fluid. J. Mol. Liq. 220, 642-648 (2016). https://doi.org/10.1016/j.molliq.2016.04.086

10. Imtiaz, M., Alsaedi, A., Shafiq, A., Hayat, T.: Impact of chemical reaction on third grade fluid flow with Cattaneo-Christov heat flux. J. Mol. Liq. 229, 501-507 (2017). https://doi.org/10.1016/j.molliq.2016.12.103

11. Bhuvaneswari, M., Eswaramoorthi, S., Sivasankaran, S., Rajan, S., Saleh Alshomrani, A.: Effects of viscous dissipation and convective heating on convection flow of a second-grade liquid over a stretching surface: an analytical and numerical study. Sci. Iran. B 26(3), 1350-1357 (2019)

12. Loganathan, K., Rajan, S.: An entropy approach of Williamson nanofluid flow with Joule heating and zero nanoparticle mass flux. J. Therm. Anal. Calorim. (2020). https://doi.org/10.1007/s10973-020-09414-3

13. Eswaramoorthi, S., Sivasankaran, S., Bhuvaneswari, M., Rajan, S.: Soret and Dufour effects on viscoelastic boundary layer flow over a stretchy surface with convective boundary condition with radiation and chemical reaction. Sci. Iran. B. 23(6), 2575-2586 (2016)

14. Loganathan. K, Mohana. K, Mohanraj, M., Sakthivel, P., Rajan, S.: Impact of 3rd-grade nanofluid flow across a convective surface in the presence of inclined Lorentz force: an approach to entropy optimization. J. Therm. Anal. Calorim. (2020), https://doi.org/10.1007/s10973-020-09751-3

15. Elanchezhian, E., Nirmalkumar, R., Balamurugan, M., Mohana, K., Prabu, K.M., Viloria, A.: Heat and mass transmission of an Oldroyd-B nanofluid flow through a stratified medium with swimming of motile gyrotactic microorganisms and nanoparticles. J. Therm. Anal. Calorim. (2020). https://doi.org/10.1007/s10973020-09847-w 
16. Liao, S., Tan, Y.A.: General approach to obtain series solutions of nonlinear differential. Stud. Appl. Math. 119(4), 297-354 (2007)

17. Liao, S.J.: An explicit, totally analytic approximation of Blasius viscous flow problems. Int. J. Non-Linear Mech. 34, 759-778 (1999)

18. Loganathan, K., Sivasankaran, S., Bhuvaneswari, M., Rajan, S.: Second-order slip, cross-diffusion and chemical reaction effects on magneto-convection of Oldroyd-B liquid using Cattaneo-Christovheat flux with convective heating. J. Therm. Anal. Calorim. 136(1), 401-409 (2019)

19. Loganathan, K., Prabu, K.M., Elanchezhian, E., Nirmalkumar, R., Manimekalai, K.: Computational analysis of thermally stratified mixed convective nonNewtonian fluid flow with radiation and chemical reaction impacts. J. Phys: Conf. Ser. 1432, 012048 (2020) 